\title{
Cultura, mídia e comportamento sexual
}

\author{
Cássia Quelho Tavares
}

\section{Introdução}

A sexualidade humana tem um profundo e nobre significado, é um bem concedido por Deus, destinado a expressar o dom de si através do qual a pessoa pode realizar-se de maneira sincera e plena. O alcance desta graça está no fato do ser humano ser capaz de superar a tendência de olhar as coisas como objetos de posse e ao outro como instrumento para sua autosatisfação. A sexualidade deve ser assumida e vivida como dom selado pelo Espírito, um caminho de percepção da presença de Deus e comunhão de amor entre as pessoas.

Infelizmente, apesar dos grandes avanços conquistados pela mídia, percebe-se uma redução significativa na compreensão e vivência da sexualidade, esvaziada de seu sentido mais profundo. Não se deve aceitar passivamente tal construção social que tem produzido banalização e até desconstrução de sua realidade mais intrínseca.

É necessária e urgente uma reflexão crítica que nos leve a compreender a sexualidade a partir de uma visão integral do ser humano.

A sexualidade humana é uma força de encontro, um dinamismo de abertura, de comunhão e de criatividade. Por outro lado, pode vir a ser também o lugar do fechamento, da posse ou dominação do outro, podendo conduzir para uma alienação na neurose ou na perversão ${ }^{1}$.

\footnotetext{
${ }^{1}$ Cf. CATECISMO DA IGREJA CATÓLICA, São Paulo, 1993, n. 2332-2333.
} 
Nesta comunicação desejamos refletir criticamente sobre a influência que os MCS têm produzido nas pessoas, principalmente no que diz respeito às mudanças comportamentais em relação à própria sexualidade, sem portanto excluir a importância da mídia.

\section{Cultura e Sexualidade}

O comportamento sexual das pessoas é expresso em parte no contexto cultural e nos estilos de vida socialmente padronizados. A cultura deve ser entendida como um processo vivo e dinâmico capaz de inferir no mundo novos modelos.

Cultura é o conjunto de sentidos e significações, de valores e padrões, incorporados e subjacentes aos fenômenos perceptíveis da vida de um grupo social concreto, conjunto que, consciente ou inconscientemente, é vivido e assumido pelo grupo como expressão própria de sua realidade humana e passa de geração em geração, conservado assim como foi recebido ou transformado efetiva ou pretensamente pelo próprio grupo ${ }^{2}$.

O meio ambiente e a cultura podem interferir no comportamento sexual das pessoas ${ }^{3}$.

Os diversos padrões de vida são provenientes do legado da experiência das gerações passadas que buscaram viver bem e reproduzir tais padrões em determinadas épocas tendo em conta suas condições políticas, econômicas, históricas, geográficas e religiosas.

$\mathrm{Na}$ sociedade ocidental judaico-cristã, por exemplo, o comportamento sexual também foi modelado a partir de fatores culturais e valores morais que ao longo da história sofreram modificações. Apesar da sexualidade na sociedade ocidental, ser norteada por um padrão moral, tem na sua prática, uma realidade polimorfa dentro da qual as pessoas se relacionam em grande medida na busca do prazer, no afeto e no companheirismo.

A cultura tem uma participação imperativa na construção comportamental. A sociedade é capaz de prover papéis elaborados que atrairão as pessoas sem que estas os busquem livremente ${ }^{4}$.

\footnotetext{
${ }^{2}$ AZEVEDO, M, Comunidades Eclesiais de Base e Inculturação da Fé, São Paulo, 1986, p. 336, em: FRANÇA MIRANDA, M, Inculturação da Fé. Uma abordagem teológica, São Paulo, 2001, p 44-45.

${ }^{3}$ Cf. História e Antropologia. Comportamento Sexual em Diferentes Culturas. Cauldron Brasil. Em: www.thecauldronbrasil $>$ com.br/article/articleview, acesso em 08/6/2007, p. 1.

${ }^{4}$ Cf. MEAD, M. Macho e fêmea. Um Estudo dos Sexos Num Mundo em Transformação, Petrópolis, 1971, p. 110-111.
} 
Alguns fatores de interferência estão envolvidos na modelagem da experiência da sexualidade, tais como as trajetórias biográficas, a experiência e a herança religiosa, as condições de vida, as redes de sociabilidade, os padrões entre os sexos, a consciência e o uso do corpo e a posição social ${ }^{5}$.

Mead faz uma distinção importante e complexa acerca do sexo no sentido das diferenças sexuais biologicamente adquiridas e do temperamento no sentido de dom individual de cada pessoa. Somente o ser humano é capaz de ter um e outro podendo valer-se dos contrastes que se apresentam mediante as diferenças temperamentais e das várias formas que a cultura humana tem de assimilar os padrões de comportamento herdados ou não-herdados ${ }^{6}$.

Deve-se considerar também que as desigualdades econômico-sociais, as diferenças culturais e raciais, as relações de dominação e de colonização podem interferir nos desejos, nas relações e nas expressões sexuais ${ }^{7}$.

Outro fator de interferência, ligado também à construção cultural, é a presença da mídia no meio social capaz, não propriamente de criar o novo, mas reforçar atitudes determinados comportamentos a partir de seu próprio interesse.

\subsection{O corpo e a mídia: reinvenção da imagem corporal}

O corpo humano, na visão cristã, reconhecido com uma função particular, contribui para revelar o sentido da vida e da vocação da pessoa. A corporeidade revela o modo próprio de existir e de operar, específico da natureza humana ${ }^{8}$.

Com o corpo, situo-me no tempo e no espaço, construo relações. Corpo é presença, expressa a cultura. Nosso corpo é marcado pela nossa história individual e social ${ }^{9}$.

Hoje, em tempos de "pós-modernidade"10, uma nova experiência acerca do corpo está se construindo. Este vem sendo substituído pelos afetos

\footnotetext{
${ }^{5}$ Cf. BOZON, M, Sociologia da Sexualidade, Rio de Janeiro, 2004, p. 97.

${ }^{6}$ Cf. MEAD, M. Sexo e Temperamento, São Paulo, 2003, p. 10-11.

${ }^{7}$ Cf. BOZON, M, op. cit., p. 97.

${ }^{8}$ Cf. SAGRADA CONGREGAÇÃO PARA A EDUCAÇÃO CATÓLICA, Orientações Educativas Sobre o Amor Humano. Linhas Gerais para uma Educação Sexual. Disponível em: www.vatican.va. Acesso em 27 jun. 2005, n. 22.

${ }^{9}$ Cf. NAVARRO, F., A Somatopsicodinâmica: Sistemática reichiana da patologia e da clínica médica, São Paulo, 1995, p. 19; cf. GEBARA, I., Conhece-te a ti mesma. São Paulo, 1991, p. 40-43.

10 Verifica-se uma diversidade de posições em relação à terminologia pósmodernidade. Para alguns autores o tempo em que vivemos já pode ser definido como "pós-modernidade", outros a chamarão de "modernidade tardia", e outros
} 
virtuais, o feminino e o masculino são caricaturados pela televisão e outros mecanismos tecnológicos capazes de manipular as imagens e as massas. Estamos diante de um verdadeiro culto ao corpo e à beleza.

Para a cultura de massas, o homem-modelo, é aquele que busca a realização em si mesmo, através do amor, do bem-estar, da beleza e da vida privada. O amor é estereotipado como sendo mitológico e ao mesmo tempo realista ${ }^{11}$.

O corpo feminino tem sido agredido pelas falsificações de imagens e pelas relações de subjetividade fechada.

A mulher continua sofrendo as conseqüências das "novas" expressões de machismos da modernidade. Em muitas circunstâncias a exploração rotineira do corpo da mulher pela propaganda tem facilitado a violência contra o feminino levando ao sério prejuízo do papel social e cultural da mulher ${ }^{12}$.

Intencionalmente a mídia constrói uma imagem corporal que é capaz de seduzir, de provocar desejos e ser invejada. Tratando-se dos programas de entretenimento, conhecidos como os "reality shows" digmática, as imagens de homem e de mulher veiculadas são de pessoas que não querem envelhecer, que estarão sempre jovens para amar e desfrutar a vida.

O final dos programas é sutilmente preparado para ter um "final feliz", com a formação de casais e a contínua renovação do corpo através da boa forma, de exercícios físicos e pela realização de provas de habilidades para que esse corpo mantenha-se em forma ${ }^{14}$.

ainda preferem determinar a terminologia como "modernidade" ou "modernidade em crise", com suas diferenciações bem caracterizadas.

${ }^{11}$ Cf. CASTRO, C. Por que os reality shows conquistam audiências? São Paulo, 2006, p. 43.

${ }^{12}$ Cf. pesquisa desenvolvida em 1990 em São Bernardo do Campo junto aos adolescentes sobre a dimensão pública da corporeidade. CASTRO, D. S. P. A dimensão pública da corporeidade: adolescência e cidadania. Em: CASTRO, D. S. P \& Outros (Org.). Corpo e Existência. São Paulo, 2003, p. 187-223; CALAZANS, G. Os jovens falam sobre sua sexualidade e saúde reprodutiva: elementos para a reflexão. Em: ABRAMO, H. W \& BRANCO, P.P.M. (Org.). Retratos da Juventude Brasileira. Análises de uma pesquisa nacional. Instituto Cidadania. São Paulo, 2005, p. 215 241.

13 A expressão "reality shows" não encontra uma tradução fidedigna, mas deve ser compreendida como sendo os programas de entretenimento que abordam a realidade cotidiana das pessoas e da sociedade através de atores reais, isto é, o ator é o próprio sujeito do drama apresentado.

${ }^{14}$ Cf. CASTRO, C., op. cit., p. 43. 
Deve-se refletir sobre o papel da mídia na definição dos padrões estéticos da população, cuja "corpolatria" é fomentada. A onda cultural insiste em dar passos para uma reinvenção da imagem corporal, onde a estética perfeita deve ser buscada e celebrada a todo custo, mesmo que venha contrapor-se a um padrão social considerado mais ético.

\subsection{A cultura das sensações}

Para Jurandir Freire muitos quadros de depressão, angústia, bulimia, anorexia, etc. são decorrentes dessa corpolatria. Uma verdadeira "epidemia de depressões leves tratadas com Prozac" 15 .

$\mathrm{Na}$ cultura do corpo fala-se em cultura das sensações. É um momento de transição da cultura dos sentimentos, que perdurou por quase três séculos, para uma cultura das sensações, onde tudo é apostado no culto ao corpo belo, não obeso e jovem. Há uma profunda infelicidade com a auto-imagem corporal $^{16}$.

A cultura das sensações preocupa-nos uma vez que vem produzindo altíssimos custos emocionais. Há uma falta de sentido de vida, que se deve a várias causas, principalmente a dificuldade de fazer projetos a longo prazo. Estamos num tempo de projetos e vínculos fragmentados, plurais e instáveis.

\section{Novo paradigma Televisivo: o efêmero está no ar}

Fala-se hoje de um novo narcisismo ou de um "tecnonarcisismo" $" 17$ que tem marcado a realidade do ser humano "pós-moderno". A mídia, sobretudo através da televisão é peça chave desse contexto ${ }^{18}$.

As telenovelas têm uma linguagem social, garantindo a quem assiste um mecanismo de compensação, produzindo a ilusão de uma ascensão social. As imagens veiculadas por esses tipos de programação integram as mais variadas e diferentes classes sociais, veiculando-se assim a idéia de que todos podem ter acesso ao objeto.

Estes programas de televisão fazem alusão ao cotidiano, ao que é mais familiar, gerando a sensação de proximidade entre o imaginário e o real. Os cenários e a dramaturgia entram nas casas e nas famílias e misturam-se como

15 ACIOLI, R. Comentário Sobre o Comportamento Sexual Feminino. Em: www.afn.org.br/comportamentosexual.pdf, acesso em: 08/6/2007, p. 2.

${ }^{16}$ Cf. ibidem, p. 1 .

${ }^{17}$ Cf. a utilização da expressão em: GUEIROS, M. C. S. Consumo, Logo Existo: Um estudo psicanalítico sobre os modismos das novelas de televisão. Dissertação de Mestrado. Departamento de Psicologia. PUC/RJ, 1993, p. 58ss.

${ }^{18}$ MAZZARINO, J. Consumidores de múltiplos tempos e espaços, em: GADINI, S L. (Org.). Fragmentos e Discursos da Cultura midiática. São Leopoldo. 2000, p. 54. 
um efeito de continuidade a ponto de interferir e penetrar nos diálogos e no dia-a-dia das pessoas. Nos horários "nobres" o crescimento do ibope cresce vertiginosamente produzindo influências na vida das pessoas e na organização social. Os horários mudam, as agendas são transferidas, tudo passa a ser secundário mediante um "último" capítulo de uma telenovela.

Há uma repetição cíclica dos capítulos, que "é um elemento importante gerador de sentimentos de permanência e continuidade ao espaço doméstico" 19 .

A televisão atua como uma espécie de ente a mais na casa, apropria-se de elementos da cultura, simula um contato direto e diário tornando o que está mais distante próximo e capaz de ser vivido ${ }^{20}$.

Nesse sentido reflete-se sobre os valores e os contra-valores produzidos que são colocados como sendo o senso comum devendo ser seguido e vivido como um ideal. Dessa maneira o comportamento sexual é também afetado.

Uma inversão perigosa vai sendo tecida e pouco a pouco surge uma nova e instável forma de se pensar e viver socialmente.

A cada nova programação em horário nobre, as polêmicas de fundo moral são colocadas, não com a intenção de despertar o senso crítico e as decorrentes escolhas, mas, trazer como moralmente lícitos e aceitáveis comportamentos até então rejeitados ou até moralmente ilícitos.

Os estereótipos fazem parte da construção cotidiana da TV e da produção cultural. Os mitos da juventude, da beleza, da perfeição física e da sedução são instrumentos eficazes na manutenção das audiências e na interferência comportamental das pessoas.

\subsection{A TV e os "reality shows"}

Para os comunicadores a televisão pode ser o lugar do entretenimento, da produção de cultura ou do espaço educativo. Cabe aqui uma breve reflexão sobre os programas de "reality shows" que marcam uma nova era na mídia, na televisão. Para nossa surpresa são conquistadores de altíssima audiência também nos países desenvolvidos.

Embora para os críticos a TV tenha uma forte possibilidade de manipulação das massas, tratando-se dos "reality shows", a crítica requer a compreensão dos fenômenos de audiência que tais programações despertam. Esse fenômeno tem acontecido numa diversidade de países, independente do nível econômico, social, cultural, religioso ou educativo ${ }^{21}$.

${ }^{19}$ GUEIROS, M. C. S., op. cit., p. 47.

${ }^{20} \mathrm{Cf}$. ibidem.

${ }^{21}$ Cf. CASTRO, C, op. cit., p. 20. 
Em tais programas o baixo custo, a alta lucratividade, o imenso poder de sedução e o envolvimento das massas estão em jogo, podendo mesmo produzir novos comportamentos sociais e culturais.

Tal êxito pode ser em parte explicado pela mistura de gêneros, trazendo a sensação de algo novo que está sendo mostrado. Reúne também na sua estrutura uma diversidade de tecnologias atendendo aos mais variados tipos de público ${ }^{22}$.

É importante ressaltar que na América Latina e aí incluído o Brasil, não há uma cultura escrita, baseada em livros. Pode-se até falar de um analfabetismo estrutural, onde não basta aprender a ler e a escrever, mas é necessário desenvolver a compreensão, a interpretação dos textos lidos, o poder de reflexão e a crítica sobre os mesmos. Temos sim e bem desenvolvida uma cultura audiovisual, que tem na TV, no rádio, no Cinema e nos DVD's as fontes acessíveis de informação e entretenimento de nossa população. shows"?

Perguntamo-nos: Por que tanto sucesso e crescimento dos "reality

As possíveis respostas apontam para o fato de centrarem-se como em um núcleo que recorda a família, algo já conhecido e seguro; as pessoas que estão no programa são comuns e anônimas, identificando-se com o telespectador; são em geral participantes jovens; o mundo dos sonhos e da imaginação está aberto a todos; uma exposição contínua de variadas formas de falar, vestir, dançar ou portar-se, o que é familiar aos diferentes grupos sociais; utilizam diferentes tecnologias de comunicação; trazem à tona assuntos e questões do cotidiano; e por fim, é um espaço onde os participantes representam a si mesmos ${ }^{23}$.

\subsection{Mercado sexual e propaganda}

Uma importante virada na maneira de pensar aconteceu com o fenômeno da industrialização, da urbanização e da mudança nas relações sociais. Uma transição desde a cultura rural até os tempos atuais capaz de produzir profundas mudanças e uma enorme crise. Outra geração se desponta. Decorre que estamos vivendo com uma sensação de amoralidade, de ausência ética, o que tem produzido insegurança, confusão e vazio acerca dos referenciais morais.

O sentido do "compromisso", da renúncia, do diálogo, parece esvaziado; tudo é fluído, líquido, volátil. É um tempo "light" e "apressado" no aspecto religioso, social e moral.

\footnotetext{
${ }^{22}$ Cf. ibidem, p. 31.

${ }^{23}$ Cf. ibidem, p. 55-56.
} 
A economia está erotizada, através da instrumentalização políticoideológica da sexualidade. Pode-se manipular de maneira direta e indireta. Diretamente, estão os artifícios da exploração sexual através da prostituição e da pornografia, os sex-shops, o mercado da estimulação sexual, os dramas sexuais explorados pela mídia, etc.; indiretamente estão os produtos ligados à sexualidade, as imagens associadas à genitalidade, os estereótipos acerca do amor e da sexualidade, as linguagens utilizadas como apelativos sexuais, as músicas, etc. Os apelos são tão fortes e presentes, muitas vezes de forma subliminar, que tudo pode ser visto e comprado sob o olhar sexual.

É a "cultura sexual" ganhando espaço com importante visibilidade gerando consumidores dependentes. É uma grande força estratégica de consumo e de manipulação. Um consumo sempre relacionado ligado ao corpo feminino e ao masculino.

$\mathrm{O}$ erotismo torna-se fermento na cultura de massas. Fala-se sobre sexo em todos os lugares, em programas de TV, nas rádios, na moda, nas escolas e rodas de debates entre jovens. $O$ problema não está em falar propriamente sobre o sexo, mas nem sempre a temática é abordada de maneira saudável e construtiva. Divulga-se a multiplicidade de parceiros, a troca de parceiros, as relações sexuais ocasionais, uma falsa liberação sexual sem culpa, que estaria sendo legitimada pela idéia de normalidade e senso comum.

O mais grave é que a sexualidade pode ser facilmente usada como elemento apaziguador dos ânimos, alienar e anestesiar principalmente a juventude, deixando-a fora das decisões político-sociais.

A indústria do sexo tem conseguido convencer que a sexualidade é constituída de um impulso irresistível, que deve ser satisfeito a qualquer preço. A compreensão da sexualidade continua sendo genitalista e fragmentada.

Parece-nos que o fator ético foi esquecido com um obscurecimento da verdade para que o mercado financeiro não seja abalado. Estamos atolados numa cultura individualista, consumista e de "morte". As consciências parecem anestesiadas diante de milhares de ofertas assumidas sem a menor reflexão ou discernimento.

\section{Uma palavra da Igreja}

A Igreja, pela voz do Magistério e da Teologia, percebe a necessidade de oferecer um criterioso discernimento, mas também acessar o diálogo através de uma humilde abertura para a escuta da sociedade ${ }^{24}$.

\footnotetext{
${ }^{24}$ Cf. JOÃO PAULO II. Carta Encíclica Veritatis Splendor (VS), São Paulo, 1993, n. 4.
} 
O amor a Deus e ao próximo deve iluminar a compreensão e a vivência da sexualidade humana ${ }^{25}$. Somente o amor, no seu real significado, pode suprir o desejo de felicidade presentes no homem e na mulher ${ }^{26}$.

Para o Magistério Eclesial apenas o amor é capaz de tornar a sexualidade verdadeiramente humana.

"A sexualidade deve ser orientada, elevada e integrada pelo amor que é o único a torná-la verdadeiramente humana, 27.

Infelizmente nem sempre a sexualidade tem sido mostrada sob a perspectiva de um amor responsável e comprometido. Para que isso aconteça não se pode prescindir de um longo e maduro processo de aprendizado, assim como uma criança que precisa percorrer um caminho, que a leve, desde os primeiros passos titubeantes, até a possibilidade de uma expressão adulta ${ }^{28}$.

A imagem de amor, desenhada em nossa sociedade e nos MCS, tem sido mostrada como pura caricatura e falsificada na sua expressividade. A Igreja está preocupada e tem procurado através da Ética Cristã iluminar o caminho, consciente que não deve prescindir da cultura e das suas expressões.

O homem ainda precisa aprender a amar; mas devemos reconhecer a grande dificuldade para que esse aprendizado se dê ${ }^{29}$.

\subsection{A liberdade e a responsabilidade diante da informação}

Há grandes e fundamentais perguntas existenciais no coração do ser humano: "Que devo fazer? Como discernir o bem do mal?". A resposta acompanha a pergunta, pois em seu interior ressoa o "esplendor da verda$d e^{, 30}$.

No Evangelho do jovem rico (Mt 19, 16-21) as questões do jovem estavam em torno do próprio significado para sua vida e como construí-la a

${ }^{25}$ Para uma compreensão mais ampla acerca do amor e da verdade, cf. GIRALDO, J., La verdad y el amor presencia de um binômio em la S. Escritura y em el Magistério, in: Studia Moralia 40/2, 2002, p. 425-465.

${ }^{26}$ Cf. AZPITARTE, E., Ética da Sexualidade e do Matrimônio. São Paulo, 1997, p. 71; cf. PONTIFÍCIO CONSELHO "JUSTIÇA E PAZ". Compêndio da Doutrina Social. São Paulo, 2005, n. 30, p. 32.

${ }^{27}$ SAGRADA CONGREGAÇÃO PARA A EDUCAÇÃO CATÓLICA, Orientações Educativas sobre o Amor Humano, www.vatican.va, 27/6/2005, n.3, p. 1.

${ }^{28}$ Cf. AZPITARTE, E., Ética da Sexualidade e do Matrimônio... op. cit., p. 71-72.

${ }^{29}$ Cf. ibidem, p. 115; para complementação sobre a arte de amar, recomenda-se a clássica e belíssima obra de FROMM, E., A Arte de Amar, Belo Horizonte, 1961; ainda sobre o amor e suas peculiaridades; e SNOEK, J., Ensaio de Ética Sexual, São Paulo, 1981, p. 147-152.

${ }^{30}$ Cf. AZPITARTE, E. Ética da Sexualidade e do Matrimônio... op. cit, p. 115. 
partir da liberdade. "Esta é efetivamente a aspiração que está no âmago de cada decisão e de cada ação humana, a inquietude secreta e o impulso íntimo que move a liberdade" ${ }^{\text {"31. }}$. A aproximação de Jesus parece levar ao extremo tais questionamentos acerca da vida e do bem moral $^{32}$.

A liberdade é devedora da consciência. No coração do ser humano está gravada a lei que o faz escolher o bem e o amor e evitar o mal. Deus a escreveu, a gravou na consciência humana, lugar secretíssimo, sacrário onde a pessoa se encontra a sós com Deus e consigo mesma ${ }^{33}$. A liberdade passa pela dinâmica da obediência profunda, ontológica, do ser humano para com esta lei, esta "voz de Deus" em sua consciência, que o vai tornando digno e verdadeiramente livre ${ }^{34}$.

A liberdade moral é uma liberdade concreta e coincide com a capacidade efetiva que o ser humano tem para orientar a sua própria existência.

Nenhuma ética autêntica pode ser entendida sem a explicação clara do que significa a liberdade e o que esta não significa ${ }^{35}$.

Uma vez dotado de inteligência, de discernimento e de decisão, o ser humano é capaz de eleger as suas escolhas a partir de sua razão e capacidade de julgamento.

Contudo as influências externas e as de caráter psico-afetivo podem condicioná-lo e manipulá-lo. A liberdade do ser humano é sempre uma liberdade situada ${ }^{36}$. Continuamente a liberdade precisa ser libertada pela fidelidade ao Deus de Jesus Cristo.

Porém, só há moral na liberdade e somente na liberdade o homem pode vencer-se a si mesmo e se converter ao bem ${ }^{37}$.

${ }^{31}$ JOÃO PAULO II., $V S . . ., o$ p. cit. n. 7, p. 16.

${ }^{32}$ Cf. ibidem, n. 8, p. 17.

${ }^{33}$ Cf. CONSTITUIÇÂO PASTORAL Gaudium et Spes (GS) n. 16, em: VIER, F. Compêndio do Vaticano II: Constituições, decretos, declarações, Petrópolis, 1989.

${ }^{34}$ Cf. VS n. 54.

${ }^{35}$ Cf. HÄRING, B., Livres e fiéis em Cristo: Teologia moral para sacerdotes e leigos. Vol. II: A Verdade vos libertará. São Paulo, 1982, p. 69; Dinâmica da Renovação, Conferência pronunciada em BH e Curitiba de 16 a 19/8/1967 - durante o Encontro Inter-Regional de Superiores e Superioras Maiores, 1967, p. 77-79.

${ }^{36}$ Cf. FRANÇA MIRANDA, M., Libertados para a práxis da Justiça. A Teologia da Graça no Atual Contexto Latino-Americano, São Paulo, 1991, p. 73-74; A Salvação de Jesus Cristo. A doutrina da graça, São Paulo: Loyola, 2004, p. 89-97; a parábola "do homem que foi colocado numa gaiola", em MAY, R., O Homem a procura de si mesmo, 13. ed. Petrópolis, 1987, p. 121-123.

${ }^{37}$ Cf. VS n. 33-34. 
"A iniciativa da nossa salvação cabe exclusivamente a Deus e nossa ação é sempre uma re-ação. Uma resposta ao seu apelo"38.

E a responsabilidade será sempre a decorrência de uma consciente liberdade. O ser humano é ético quando alia liberdade e responsabilidade.

Compreender esses pressupostos é indispensável para alicerçarmos um maduro discernimento acerca da utilização e absorção da informação midiática que tem encontrado espaço aberto no cotidiano das pessoas.

\subsection{O seguimento de Jesus Cristo}

"Seguir a Jesus é viver o radicalismo do amor, que leva a entregar a vida pelos outros" 39 .

Uma das finalidades por excelência da ética é reconhecer a pessoa na sua dignidade e integridade, negando todo tipo de fragmentação. Considerar o ser humano em todas as suas dimensões e expressões, levando em conta as etapas de sua vida ${ }^{40}$.

Decorre que a ética cristã está fundamentada em Jesus Cristo e no seu seguimento.

Em Jesus, o ser humano é assumido como pessoa e reconhecido como aquele que é capaz de construir relações, capaz de comunhão, mas por outro lado, é um ser inacabado, em crescimento e aperfeiçoamento contínuos ${ }^{41}$.

A ética sexual cristã aponta para uma vivência integrada da sexualidade, a partir dos valores cristãos que estão enraizados no seguimento de Jesus Cristo.

Somente a partir de Jesus Cristo pode-se ter uma visão do homempessoa na sua integralidade, cujo chamado de Deus se dá em favor da Vida, lançando fora todo tipo de individualismo, de dualismo e de exclusão ${ }^{42}$.

\subsection{Uma pastoral integradora e formadora de opinião crítica}

Uma pergunta pode ser feita: a Mídia tem sido escola, lugar de formação? Querendo ou não, muitas vezes sentimo-nos imobilizados diante do

\footnotetext{
${ }^{38}$ FRANÇA MIRANDA, M., Libertados para a práxis..., op. cit., p. 79.

39 AZPITARTE, E., Fundamentação..., op. cit., p. 251. Para ampliar as definições, cf. p. 49-50.235-236.252-253.

${ }^{40}$ Cf. AGOSTINI, N., Introdução à Teologia Moral. O que você precisa viver e saber. $4^{a}$ ed. Petrópolis, 1997, p. 99; cf. PAULO VI. Carta Encíclica Humanae Vitae. 9. ed. São Paulo, 2001, n. 1-6.

${ }^{41}$ Cf. AGOSTINI, N., Introdução à Teologia Moral..., op. cit., p. 71.

${ }^{42}$ Cf. ibidem, p. 97-99; cf. JOÃO PAULO II, Evangelium Vitae. 2. ed. São Paulo, 1995, n. 2, p. 6-8.
} 
grande poder de influência e manipulação que a mídia infere sobre a sociedade.

A pastoral precisa de alguma maneira aproximar-se do coração do homem "pós-moderno", percebendo suas inquietações, dores e esperanças. O anúncio do Evangelho chegará melhor aos corações na medida em que houver abertura à escuta dos anseios do ser humano. Trata-se de uma postura antropológica indispensável: o homem e a mulher devem ser contemplados e acolhidos naquilo que são, na sua integralidade, com suas dúvidas, projetos e limites; e o Senhor que anunciamos é um Deus Encarnado, presente no coração e na história dos homens, isto é, na cultura dos povos.

É urgente evangelizar a sociedade fazendo emergir valores indispensáveis acerca da sexualidade humana e outros temas afins. Os leigos são os protagonistas para que tais valores, presentes no Evangelho, possam chegar nos mais variados ambientes que lhes compete atuar e influenciar.

Não são poucos os lugares e os meios para uma evangelização efetiva e eficaz. Verdadeiramente todo cristão é chamado a ser sal da terra e luz do mundo (cf. Mt 5, 13-14), e são muitos os desafios em meio à difusão de uma cultura de morte; do indiferentismo religioso; do ateísmo prático, das conquistas técnico-científicas marcadas pela globalização; enfim, do secularismo declarado, marcado, sem sombra de dúvidas, pelo fenômeno da descristianização e da desvinculação com o outro.

Precisamos aprender a aprender; aprender a pensar e a conhecer; aprender a fazer; aprender a ser; aprender a conviver com os outros, nossos semelhantes e irmãos; aprender a aceitar e a conviver com o diferente; aprender, enfim a continuar aprendendo ${ }^{43}$.

A pastoral é um desses lugares onde as perguntas estão sendo feitas... mas nem sempre devidamente respondidas.

\section{Conclusão}

A fé cristã é muito clara quando aponta as verdadeiras qualidades para uma sexualidade integrada e construída no amor, com orientações para pensar, aprender, falar e viver a linguagem sexual. Por isso não pode eximir-se da reflexão quanto aos meios utilizados, sobretudo pela mídia.

Os MCS são indispensáveis para a vida social. A mídia tem o seu valor. A sociedade atual não funciona sem sua presença, produtora de difusão do conhecimento, lazer, convivência entre as pessoas e grupos sociais. E estes deveriam empreender maiores esforços na divulgação de valores capazes de construir uma sociedade mais saudável.

${ }^{43}$ Cf. LIBÂNIO, J. B., A arte de formar-se, São Paulo, 2001. 
Há benefícios louváveis, mas também lamentáveis prejuízos e massificações irreparáveis. Instala-se através dos MCS ao mesmo tempo um processo construtor mas também deformador do pensamento.

A teologia moral está profundamente comprometida na direção e orientação dos costumes humanos a partir de um discernimento criterioso em consonância com a escuta contínua da Palavra de Deus, do conselho oriundo do Magistério Eclesial e da defesa de uma visão integrada do homem enraizada na história de seu tempo.

Para que isso se dê é indispensável colocar-se à caminho no seguimento de Jesus Cristo, vivendo o seu amor no desprendimentoencarnação-serviço. Trata-se de reconhecer Jesus Cristo da maneira como ele se definiu, como coerentemente se entregou, sendo um homem verdadeiro inserido num meio histórico e igualmente sendo Deus a fim de que conhecêssemos e participássemos do mistério divino ${ }^{44}$.

Cássia Quelho Tavares Doutoranda em Teologia PUC/RJ Professora Substituta da Escola de Enfermagem Anna Nery (Departamento Materno-Infantil) UFRJ.

${ }^{44}$ Cf. DURAND, G., Sexualidade e Fé. São Paulo, 1989, p. 46. 